\title{
POWER GENERATION AND CONTROL OF A SELF EXCITED SQUIRREL CAGE INDUCTION GENERATOR
}

\author{
M. A. Oriahi ${ }^{1, *}$ and J. O. Egwaile ${ }^{2}$

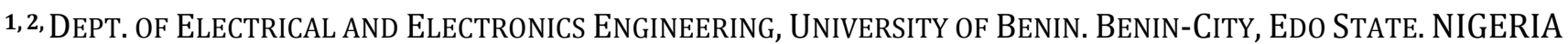 \\ Email addresses: ${ }^{1}$ mattheworiahi@yahoo.com, ${ }^{2}$ joeranky@yahoo.com
}

\begin{abstract}
The self-excited squirrel cage induction generator (SEIG) is frequently considered as the most economical solution for powering customers isolated from the utility grid by wind energy because it derives its excitation from its own output terminal and neither an exciter nor voltage regulator is required. Its major drawbacks, however, are poor voltage and frequency regulation under variable load conditions. The aim of this paper is to investigate a feedback control strategy that takes a fraction of the output power and applies it to the prime mover as torque. The wind turbine is to be tied mechanically to the rotor of a squirrel cage induction which is fed with grid powerthat the generator supplies. A back to back converter is used to maintain a constant voltage/frequency relationship at the motor terminals. The implication of this model is investigated. The performance characteristics of the machine for various machine variables are also investigatedusing the MATLAB/SIMULINK environment.
\end{abstract}

Keywords: Wind Power systems, Self-excited squirrel cage induction generator, squirrel cage induction motor, backto-back converter, simulation.

\section{INTRODUCTION}

It has been found that the self-excited squirrel cage induction motor can also be used to generate electricity. An induction generator may then be defined as an induction motor whose electrical performance has been modified to optimize its performance as a generator. The possibility of using a capacitor bank connected across the stator terminals of a squirrel cage induction motor to supply the reactive power requirement for power generation was discovered by Basset and Potter in the 1930s It is more attractive than a conventional synchronous generator in microhydro and wind turbine application because of the absence of a DC excitation source, brushless cage rotor construction and lower maintenance costs $[1,2,3]$. Its main disadvantage, however, is that the reactive power of the excitation capacitors is shared by both the machine and the load which directly affects the excitation of the machine resulting in its poor voltage and frequency regulations under variable load conditions.

When a self-excited squirrel cage induction machine is driven by a prime mover, rotor speed induced voltages appear in the stator windings which drive current through the capacitor bank connected at the stator terminals, establishing a magnetising flux in the machine [4]. The induced emf and current in the stator windings will rise and oscillate, influenced by the residual magnetic flux in the rotor magnetic field until steady state is attained. The magnitude of the steadystate voltage generated is determined by the magnetizing currents, the value of the self-excitation capacitance, the rotor speed, the machine parameters and the terminal load. As the load changes, the demand for leading VArs also changes and if the speed of the turbine is not regulated, then both the magnitude and frequency of the AC voltage across the machine terminals will vary with the power demand of the load $[5,6]$.

A doubly fed induction generator, in which both the rotor and stator windings are electrically excited, offers the benefits of both a synchronous and an induction machine. The wound rotor is fed through slip rings and brushes. However, because they operate at relatively higher speeds, they require high-speed gearboxes to convert the slow-turning shaft of a wind power system, resulting in extra maintenance costs and difficulty in complying with grid codes. The use of a pole changing method of SEIGs has also been investigated in order to capture more wind energy under variable wind speed conditions [7, 8]. It was observed that the stator current was smaller, the capacitor requirement was 
less (around 44\%) and power output was about 2.5 times larger in a four-pole than the corresponding results from a six-pole configuration.

Many studies of the steady-state and transient performance of SEIGs driven by both regulated and unregulated turbines have been presented $[9,10]$. Although many of them have focused on regulating the voltage and frequency of the SEIG, these regulations have not resulted in a satisfactory level of performance of the machine. An innovative solution of the steadystate and transient analysis of operating of any number of SEIGs in parallel has been presented [11]. The steady-state performance of a standalone SEIG with a transformer connected to its terminal has also been analyzed [12]. The transformer was used to match the generator impedance with the grid and to make the generated voltage compatible with the grid voltage. This, however, introduced additional nonlinearity into the system which complicates the analysis.

\section{MODELING THE AUTONOMOUS SELF EXCITED INDUCTION GENERATOR.}

When a physical system (or device) is disturbed by an external forcing function, the disturbance causes the system variables to undergo a transient variation. An induction machine is inherently non-linear, and this nonlinear behaviour can be significantly reduced by mixing a proportion of the output signal with the input signal [13]. From the simple feedback scheme of Fig.1a, it can be deduced that:

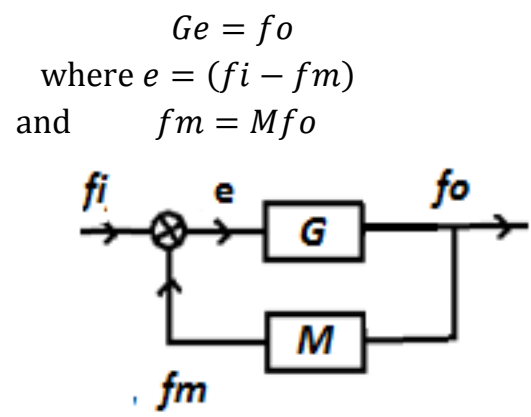

(a):The Simple Squirrel cage generator.
Hence $\quad f o / f i=G /(1+G M)$,

where $\mathrm{G}$ is the system, $\mathrm{M}$, is the feedback element and $\mathbf{e}$ is the error signal which acts to minimize the error [14]. Clearly, if the product,GM, called the "open loop gain", can be made high compared to 1 , the resulting "closed loop gain", 1/M will be essentially independent of G.

In this simple system, $f i$, fo and $f m$ are all of the same unit. However for a system that has more than one variable, the equation implied by $G e=f o$ cannot possibly be correct since $\mathrm{H}$ is depicted as a constant multiplier. In order for us to use a figure such as this, we must add a component $\mathrm{C}$ in the feedback loop, as shown (Fig.1b), which enables us to construct the input signal we can apply to M [15].

In mathematical form,

$$
\begin{array}{ll} 
& (\text { Tin }-\mathrm{Tm}) \omega_{1}=\mathrm{Pg} \\
\text { and } & \mathrm{Tm} \times \omega_{2}(1-s)=\text { Pmech }
\end{array}
$$

where Tin is the mechanical torque applied on the prime mover by wind power, Tmis thebraking torque of the motor and $\mathrm{Pg}$ is the total mechanical energy converted into electrical energy in the generator output per phase, where $\omega_{1}$ is the rotational speed of the prime mover. Pmech is the power converted into mechanical motion in the motor, where $\omega_{2}$ is the rotational speed of the motor and $s$ is the slip.

The component $\mathrm{C}$, may take the form of a cyclo converter, that takes power at one voltage and frequency and delivers it at another voltage and frequency, or in the form of a back to back AC/DC/AC converter that does essentially the same in just about two stages.

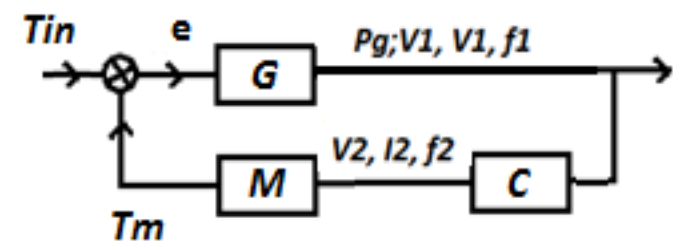

(b): The Modified Squirrel cage generator. Fig: 1: System equation in Block diagram form

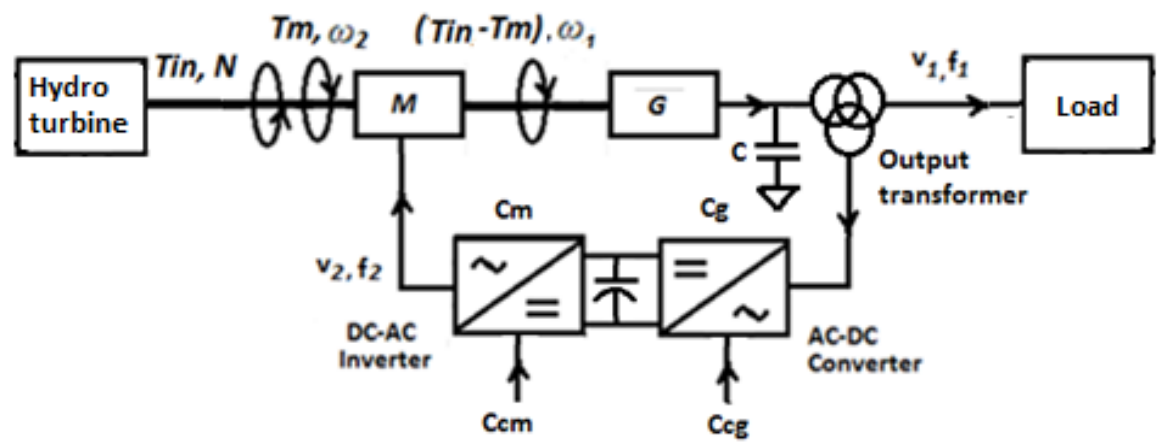

Fig: 2: The proposed circuit diagram of a Cage motor controlled self-excited Squirrel cage generator. 


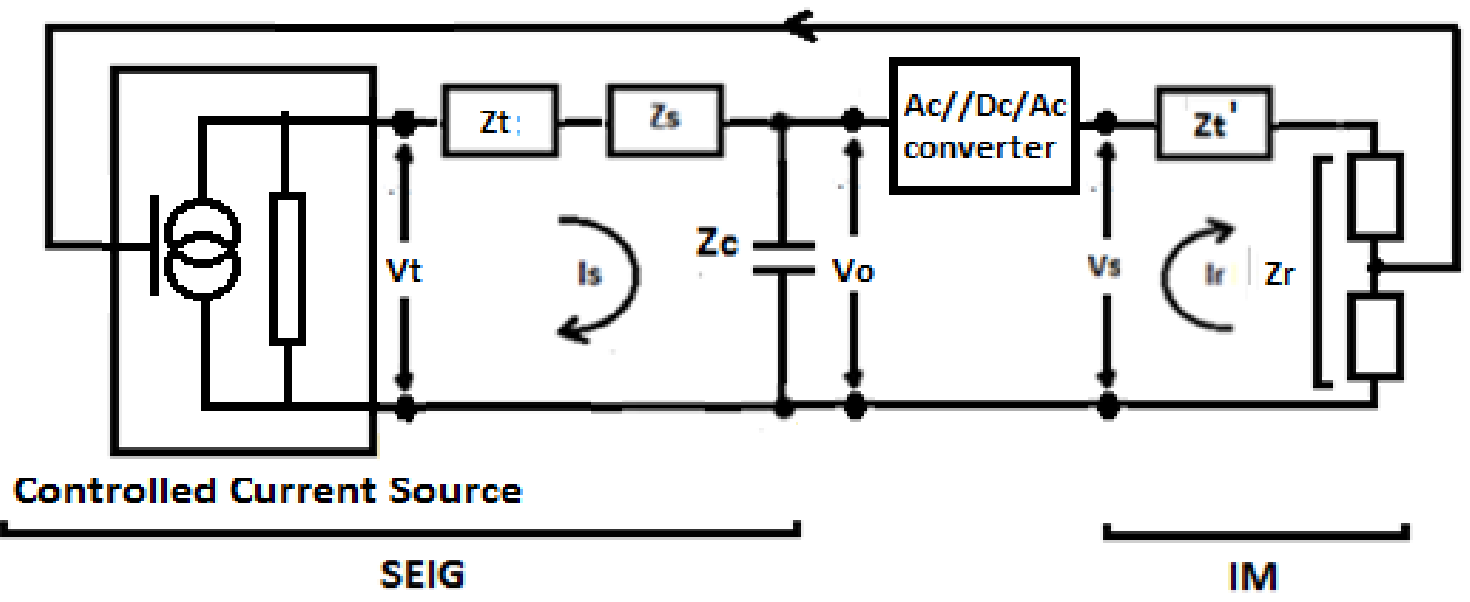

Fig: 3: The per phase Equivalent circuit of the composite SEIG

In the back to back converter shown in Fig.2, the grid side converter (Cg)accepts AC power from the generator and converts it to $\mathrm{DC}$ power, while the motor-side converter $(\mathrm{Cm})$ force-commutates the DC voltage into alternating current at the desired frequency. The performance characteristics of the squirrel cage motor may be evaluated on per phase basis using a T- network. This may be converted into the Thevenin equivalent form of a series impedance for convenience. Similarly, it may be converted into the Norton equivalent form of a series impedance driven by a current source. The idea of a current source driving current directly into the rotor circuit of an induction motor, when suitably excited and driven by an external prime mover, forms the basis of our circuit model of the self-regulated SEIG as shown in Fig. 3. The power captured by the wind turbine drives the SEIG to generate electrical energy. Part of this energy is passed through an AC/DC/AC converter to the induction motor (IM) which returns it as electromagnetic torque in the form of current to regulate the current source.

Now,

$$
P_{\text {in }}=V_{t} I_{s} \cos <_{I_{s}}^{V_{t}}=\frac{V_{t}^{2}}{\left|Z_{t}+Z_{s}+Z_{c}\right|}
$$

The total energy at the generator output per phase is given by the relation,

$$
\begin{gathered}
P_{g}=\frac{\left|Z_{C}\right|}{\left|Z_{t}+Z_{s}+Z_{c}\right|} P_{\text {in }}=\frac{\left|Z_{C}\right|}{\left|Z_{t}+Z_{s}+Z_{c}\right|^{2}} \times V_{t}^{2} \\
=\left|Z_{C}\right| \times I_{s}^{2}
\end{gathered}
$$

In (8) $\mathrm{Z}_{\mathrm{t}}=\mathrm{Z}_{\mathrm{m}} \| \mathrm{Z}_{\mathrm{r}}=\mathrm{R}_{\mathrm{t}}+\mathrm{j} \mathrm{X}_{\mathrm{t}}, \quad \mathrm{Z}_{\mathrm{s}}=\mathrm{R}_{\mathrm{s}}+j X_{s} \quad$ and $Z_{c}=-j X_{c}$. If a fraction of the output voltage is applied to the motor winding, we can infer that the power delivered to the motor per phase is;

$$
P_{m}=\frac{\left|Z_{C}\right|}{\left|Z_{t}+Z_{s}+Z_{c}\right|^{2}} \times\left(\frac{f_{1}}{f_{2}}\right)^{2} \mathrm{~V}_{\mathrm{t}}=\left(\frac{f_{1}}{f_{2}}\right)^{2} P_{g}
$$

where $\frac{f_{1}}{f_{2}}$ is the ratio of the input and output supply frequencies.

The power converted into mechanical motion in the motor is:

$$
P_{\text {mech }}=\frac{R_{r}(1-s) / s}{\left|Z_{t}^{\prime}+Z_{r}\right|^{2}} P_{m}
$$

where $\mathrm{Z}_{\mathrm{t}}^{\prime}=\mathrm{Z}_{\mathrm{m}} \| \mathrm{Z}_{\mathrm{sr}}=\mathrm{R}_{\mathrm{t}}^{\prime}+\mathrm{j} \mathrm{X}_{\mathrm{t}}^{\prime}$ and $Z_{r}=R_{r} / s+j X_{r}=$ $R_{r}+\frac{R_{r}(1-s)}{s}+j X_{r}$

Using equations (5) and (6), we get

$$
P_{g}=\left[T_{\text {in }} \omega_{1}-\frac{\omega_{1} R_{r}(1-s) / s}{\omega_{2}(1-s)\left|Z_{t}^{\prime}+Z_{r}\right|^{2}} P_{m}\right]
$$

Substituting for $P m$ from (9), we get

$$
P_{g}\left[1+\frac{\omega_{1} R_{r}(1-s) / s}{\omega_{2}(1-s)\left|Z_{t}^{\prime}+Z_{r}\right|^{2}}\left(\frac{f_{1}}{f_{2}}\right)^{2}\right]=T_{i n} \omega_{1}
$$

from which:

$$
T_{i n}=\frac{P_{g}}{\omega_{1}}\left[1+n^{3} \frac{R_{r} / s}{\left|Z_{t}^{\prime}+Z_{r}\right|^{2}}\right]
$$

where $n=\frac{\omega_{1}}{\omega_{2}}=\frac{f_{1}}{f_{2}}$

\section{SIMULATING THE SEIG}

Unlike a traditional induction machine, the characteristics of an SEIG depend not only on the applied stator voltage, but also on the injected rotor voltage. The amplitude and phase angle of the AC voltage measured at the grid terminals changes as the real and reactive power control vary.The reactive power at the grid terminals can be generated or absorbed by a back to back converter and exchanged between the converter and the grid through the generator. MATLAB/SIMULINK simulation is used to assess the behaviour of the SETG in a single mathematical package. The machine characteristics of torque, power, phase voltage, phase current due to loading are all included in the simulation.

If we make $n^{3} \frac{R_{r} / s}{\left|Z_{t}^{\prime}+Z_{r}\right|^{2}} \gg 1$, equation (13) reduces simply to:

Vol. 36, No. 4, October 2017 


$$
T_{\text {in }}=\frac{P_{g}}{\omega_{1}} n^{3} \frac{R_{r} / s}{\left|Z_{t}^{\prime}+Z_{r}\right|^{2}}
$$

That is:

or

$$
T_{i n}=\frac{P_{g}}{\omega_{1}} n^{3} \frac{R_{r} / s}{\left(R_{t}^{\prime}+R_{r} / s\right)^{2}+\left(\mathrm{X}_{\mathrm{t}}^{\prime}+X_{r}\right)^{2}}
$$

$$
T_{\text {in }} \approx \frac{P_{g}}{\omega_{1}} n^{3} \frac{R_{r} / s}{\left(R_{t}^{\prime}\right)^{2}+\left(\mathrm{X}_{\mathrm{t}}^{\prime}+X_{r}\right)^{2}}
$$

since $R_{t}^{\prime}>R_{r}$ and $R_{r} / s$ decreases very rapidly for increasing values of $\mathrm{s}$,

Thus we can write:

$$
T_{\text {in }}=\frac{A}{S}
$$

where $A$ is a constant and

$$
T_{\text {in }}=B n^{3}
$$

where B is a constant,

These equations show that power and torque decrease very rapidly as $s$ increases and increase very rapidly as $n$ increases, which indicates that at some value of $n=S$, at which the two curves converge, we can obtain a value the optimum value of power and torque and the points at which they occur.

\section{RESULTS AND ANALYSIS}

Plots of the two curves on the same graphic window with two sets of $\mathrm{x}$ data ( $n$ and $s$ ) for one set of $\mathrm{y}$ data (shown in Fig. 4) reveals that apoint of intersection of the curves occurs in the braking range of the motor at $n \approx s \approx 1.09$, when $\mathrm{A}=1$ and $\mathrm{B}=2$. Also, from the relation:

$$
T_{m}=\frac{P_{g}}{\omega_{1}} n^{3} \frac{R_{r} / s}{\left|Z_{t}^{\prime}+Z_{r}\right|^{2}}=\frac{R_{r} / s}{\left|Z_{t}^{\prime}+Z_{r}\right|^{2}} n^{3} \times I_{S}^{2}\left|Z_{C}\right|
$$

we get

$$
I_{s}=\sqrt{\frac{s\left|Z_{t}^{\prime}+Z_{r}\right|^{2} T_{m}}{n^{3} Z_{C} \mid R_{r}}}=C \sqrt{s / n^{3}}
$$

where $\mathrm{C}$ is a constant.

Plots of $I_{s}$ vs $s$ for $n=1.09$ and varying values of $C$ indicates that the generator stator current rises very rapidly under no load condition beyond the optimum operating point if $\mathrm{C}=4$ as shown in Fig. 5. From this graph, we make the following observations:

i. The generator stator current rises linearly for all values of $n<s$ and exponentially for all values of $n>s$.

ii. There is a critical value of $n=s$ for which the stator current becomes excessive.

iii. The ratio of $f_{1}$ and $f_{2}$ or $n$ represents a distribution of voltage between the converter and the motor winding, while the ratio of $f_{r}$ and $f_{2}$ or $s$ represents a distribution of current between the converter and the rotor. iv. Any variation in the load, which is indicated directly by the variation in the terminal voltage and current of the generator, causes a corresponding appropriate response by the motor through the converter.

\section{MODELLING THE BACK TO BACK CONVERTER}

The back to back converter consists essentially of a controlled rectifier (T1) and an inverse parallel controlled rectifier (T2). The grid side converter is used to generate or absorb the grid electrical power and stores it as fixed Dc in a capacitor, while the motor side converter inverts the stored energy into alternating current Ac at desired voltage and frequency. The control circuit constructs the control signal to the grid side converter (Ccg) by pulse angle modulation box, PAM, while the motor side converter constructs the control signal to the motor side converter ( $\mathrm{Ccm}$ ) by pulse width modulation box, PWM. A second level control system is be added as shown for user control purposes. The controller should provide a rapid and accurate response from the reference voltages and currents.

\section{SIMULATING THE AC-DC-AC CONVERTER}

The model equations are derived as follows: Input voltage of the form $v_{s}=V_{s} \sin \omega t$ is converted into Dc in the capacitor and the charging current through diode is:

and

$$
i_{d}=i_{C}+i_{R}=C \frac{d}{d t} v_{c}+\frac{V_{C}}{R}
$$

$$
\begin{gathered}
V_{c}=\frac{2 V_{s m}}{\pi} \\
i_{M}=A\left[\cos (\omega t-\Phi)-B e^{-t / r}\right]
\end{gathered}
$$

where $\mathrm{A}$ and $\mathrm{B}$ are constants, $\mathrm{r}=\mathrm{L}_{\mathrm{M}} / \mathrm{R}$ and $\Phi=\tan ^{-1}$ $\omega L_{M} / R$. We know that under initial conditions, $i_{M}$ is zero so that $A \cos (-\Phi)=B$. Since $\Phi=\tan ^{-1} \omega L_{M} / R$, $\left.\left|Z_{M}\right|=\sqrt{(R}+j \omega L_{M}\right)$ and $\cos \Phi=R /\left|Z_{M}\right|$ so that $B=A \times R /\left|\mathrm{Z}_{\mathrm{M}}\right|$. Now for a motor of 0.8 power factor (usually), $\cos \Phi=\frac{R}{\left|Z_{M}\right|}=0.8$ so that $\Phi=\tan ^{-1}\left(\frac{6}{8}=\right.$ 0.75 ) and equation (23) may be written as:

$$
i_{M}=A\left[\cos (\omega t-0.64)-0.8 \exp ^{(-\omega t / 0.75)}\right]
$$

where $\omega=2 \pi f_{2}$ at the new frequency.

The simulation of equation (24) for $f_{2}=\frac{f_{1}}{1.09}$, where $f_{1}$ is the supply frequency, and $A=1$, is shown in Fig.7, which indicates that sudden transients, due to variations in load and other causes, are effectively subdued within a very short period of time, leaving only the steady alternating current in due course. 


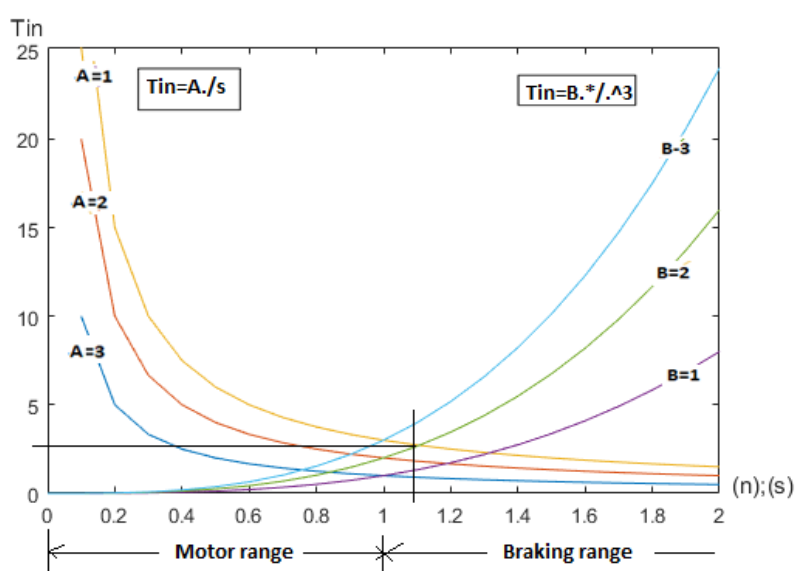

Fig: 4: Simulation of Tin $=A / s$ and of Tin $=B n^{3}$ for varying values of $A$ and $B$

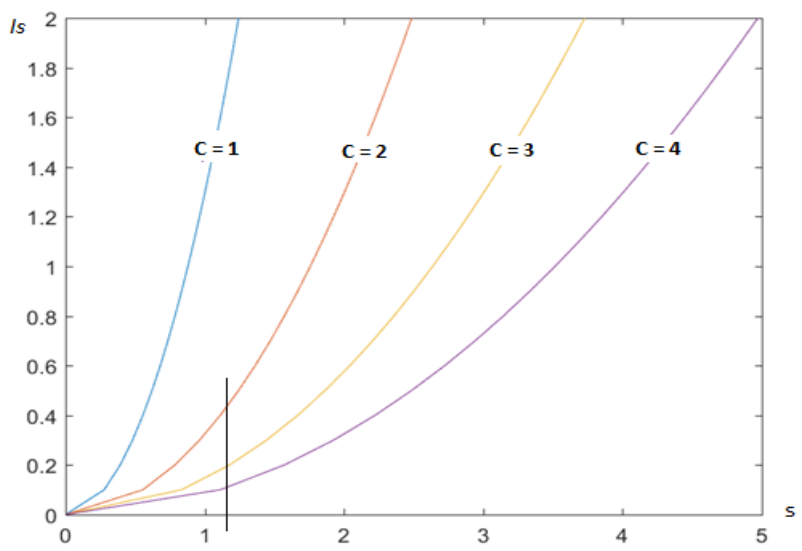

Fig: 5: Simulation of Is vs $s$ for $n=1.09$ and varying values of $C$

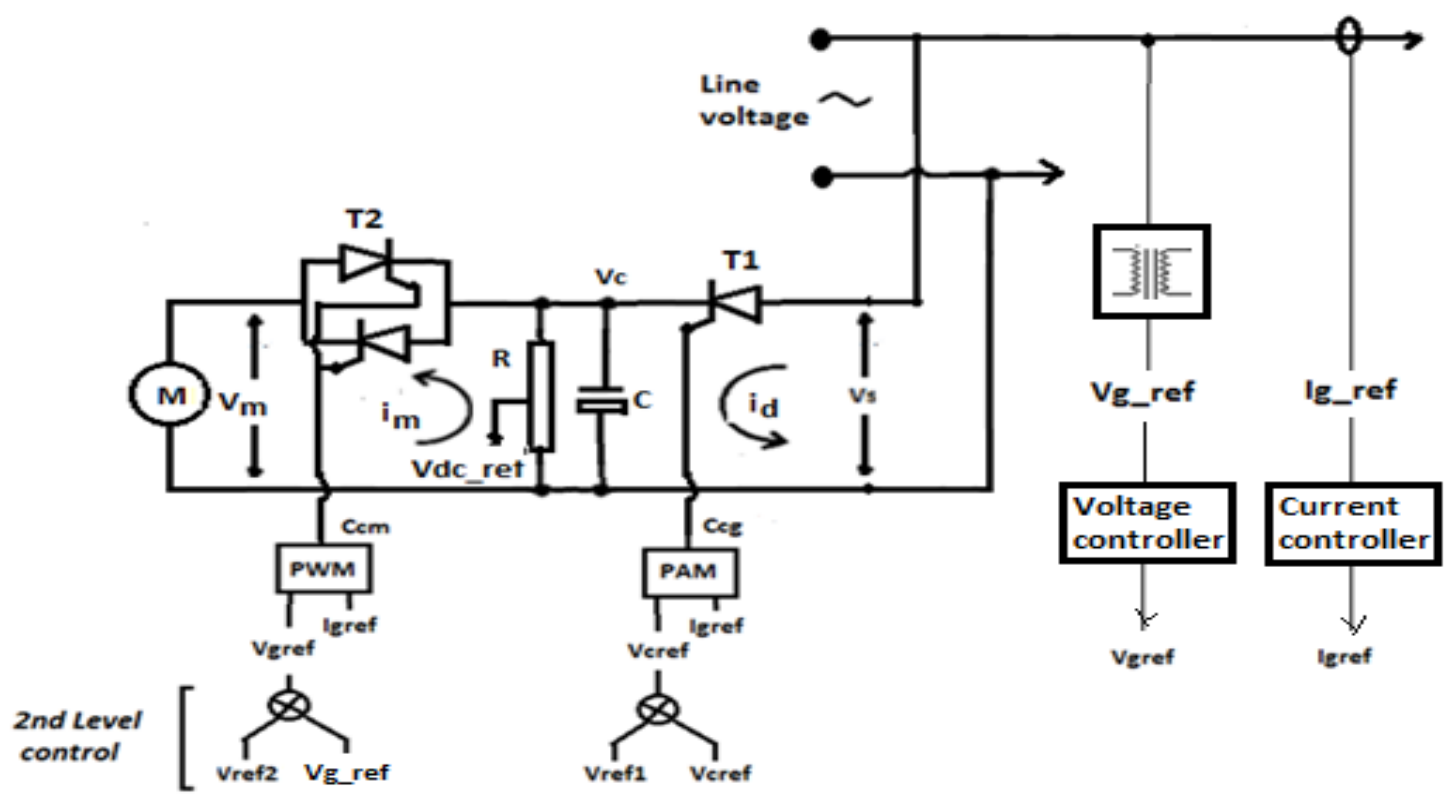

Fig: 6: Model of Back to Back converter

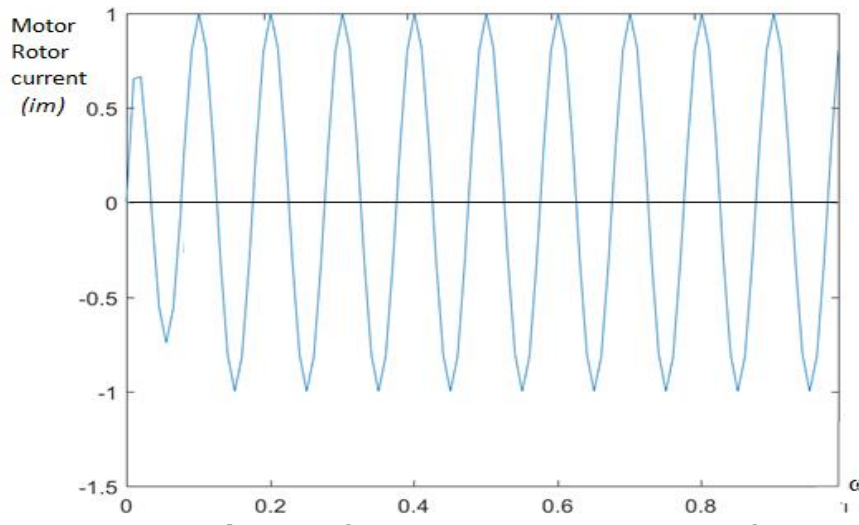

Fig: 7: Simulation of Motor rotor current vs $\omega t$ for

$$
\frac{f_{1}}{f_{2}}=1.09 \text { and } A=1
$$

\section{CONCLUSION}

Modern wind turbines have become an economically competitive form of clean and renewable power generation. In this study, the performance analysis of a standalone self-excited, self-regulated, squirrel cage induction was simulated using MATLAB. Aback to back $\mathrm{AC}$ converter was used to control a feedback motor that regulates the generator output and frequency. From the simulation analysis it is clear that by operating an SEIG in tandem with a squirrel cage induction motor such that $s=\frac{f_{\mathrm{r}}}{f_{\mathrm{s}}}=n$, the dynamic performance of the SEIG can be significantly improved. No attempt has been made to determine the efficiency of the system.

\section{REFERENCES}

[1] E. D. Basset and F. M. Potter, "Capacitive Excitation for Induction Generators," Transactions of the American Institute of Electrical Engineers, vol. 54, no. 5, pp. 540-545, May 1935.

[2] Dandan Ma, Self-excited Induction Generator - A Study Based on Nonlinear Dynamic Methods, 
School of Electrical and Electronic Engineering Newcastle University United Kingdom, May, 2012.

[3] R. C. Bansal, "Three-Phase Self-Excited Induction Generators: An Overview," IEEE Transactions on Energy Conversion, vol. 20, no. 2, pp. 292-299, June 2005.

[4] 0. Anaya-Lara, N. Jenkins, J. Ekanayake, P. Cartwright, M. Hughes, Wind Energy Generation: Modelling and Control, Wiley, 2009.].

[5] J. M. Elder, J. T. Boys and J. L. Woodward, "Selfexcited Induction Machine as a Small Low-cost Generator," IEE Proceedings C on Generation, Transmission and Distribution, vol. 131, no. 2, pp. 33-41, March 1984.

[6] Mohamed Barara et. al, General study of selfexcited induction generator used in isolated renewable energy conversion source Ola-22.pdf]

[7] S. C. Agarwal and M. Singh, "An Analysis of Selfexcited Pole Changing Induction Generators," in Proceedings 8th National Power System Conference, Delhi, India, December 14-17, 1994.

[8] J. K. Chatterjee and P. K. S. Khan, "Excitation Capacitor Requirement and Performance of Pole Changing Self-excited Induction Generator Operating with Unregulated Prime Mover," in Proceedings 9th National Power System Conference, Kanpur, India, December 19-21, 1996.

[9] T. F. Chan, "Self-excited Induction Generators Driven by Regulated and Unregulated Turbines,"
IEEE Transactions on Energy Conversion, vol. 11, no. 2, pp. 338-343, June 1996.

[10] Martin Healy, Principle of Automatic Control, Hodder and Stoughton Publishers, 1981.

[11] S. M. Alghuwainem, "Steady State Analysis of a Self-excited Induction Generator Including Transformer Saturation," IEEE Transactions on Energy Conversion, vol. 14, no. 3, pp. 667-672, September 1999

[12] E. D. Basset and F. M. Potter, "Capacitive Excitation for Induction Generators," Transactions of the American Institute of Electrical Engineers, vol. 54, no. 5, pp. 540-545, May 1935.

[13] F. A. Farret, B. Palle and M. G. Simoes, "Full Expandable Model of Parallel Self-excited Induction Generators," IEE Proceedings on Power Applications, vol. 152, no. 1, pp. 96-102, January 2005.

[14] G. K. Singh, "Self-excited Induction Generator Research - a Survey," Electric Power Systems Research, vol. 69, no. 2-3, pp. 107-114, May 2004.

[15] Thaler G., Wilcox M., “Electrical Machines”, John Wiley \& Sons Publishers, New York, 1966.

[16] John Billingsley, Controlling with computerscontrol theory and practical digital systems, McGraw Hill Coy (UK) Limited, 1989.

[17] Theraja B. L., A text book of Electrical Technology, Volume II, AC \& DC Machines, S. Chand and Company Publishers, 1978. 